\title{
GMR
}

\section{Genetic diversity analysis of Aspergillus flavus isolates from plants and air by ISSR markers}

\author{
M.A. Mahmoud', A.M.A. El-Samawaty ${ }^{1,2}$, M.A. Yassin ${ }^{1,2}$ and A.R.M. Abd El-Aziz ${ }^{2}$ \\ ${ }^{1}$ Plant Pathology Research Institute, Agricultural Research Center, Giza, Egypt \\ 2Botany and Microbiology Department, College of Science, King Saud University, \\ Riyadh, Saudi Arabia \\ Corresponding author: M.A. Mahmoud \\ E-mail: m.a.mahmoud75@gmail.com \\ Genet. Mol. Res. 15 (2): gmr.15028081 \\ Received November 18, 2015 \\ Accepted January 21, 2016 \\ Published April 27, 2016 \\ DOI http://dx.doi.org/10.4238/gmr.15028081
}

ABSTRACT. Aspergillus flavus is one of the most abundant and widely distributed fungi on earth. A. flavus produces aflatoxins (AFs), which are toxic secondary metabolites. AFs have harmful effects on public health (humans and animals) and agricultural crops. Inter-simple sequence repeat (ISSR) markers were used to analyze the genetic diversity of 30 A. flavus isolates from five agricultural crops and air. Genetic similarity coefficients (GSC) ranged from 0.51 to 0.10 based on three ISSR markers for the isolates tested. A. flavus isolates grouped into 6,5 , and 3 clusters using the unweighted pair-group method with arithmetic average of three ISSR markers. This study suggests that ISSR biotechnology is a highly useful tool for characterizing genetic diversity of $A$. flavus isolated from different sources.

Key words: Aspergillus flavus; Inter-simple sequence repeats; Genetic diversity 


\section{INTRODUCTION}

Aspergillus is one of the most economically important genera, involving more than 185 species with diverse impacts on the health of humans, animals, and plants. The majority of these species commonly inhabits foods, plants, and soil, and is even found in air (Yu et al., 2005). The delicate analysis of genetic diversity has considerable implications for molecular plant breeding strategies and biological control in plant disease programs (Kumar, 1999). Recently, advanced molecular biology techniques, such as DNA profiling based on amplified fragment length polymorphisms (AFLP) (Singh et al., 2015), restriction fragment length polymorphisms (RFLPs) (Mohankumar, et al., 2010), random amplification of polymorphic DNA (RAPD) (Mahmoud et al., 2014), microsatellites or simple sequence repeats (SSR) (Mushtaq et al., 2015), expressed sequence tag-simple sequence repeats (EST-SSR) (Wang et al., 2012), short tandem repeats (STR) (Houshyarfard et al., 2015), and intersimple sequence repeats (ISSR) (Zhang et al., 2013; Chhotaray et al., 2015), have been widely used for the characterization of genetic diversity in A. flavus.

ISSR-PCR is a genotyping technique based on length variation in the regions between microsatellites, with high discriminatory power of amplified DNA (Prince, 2015). Primers can be various combinations of di-, tri-, tetra-, and penta-nucleotide repeats, targeting multiple genomic loci to amplify ISSR sequences of various sizes (Reddy et al., 2002). The method is rapid and highly reproducible (unlike RAPD) as well as being fast and relatively inexpensive and less timeconsuming (unlike AFLP and RFLP) (Varga, 2006), with the complexity of SSR (Chen et al., 2008). It thus combines the advantages of RAPD, AFLP, and SSR (Abadio et al., 2012).

In plant-pathogenic fungi, ISSR technology has been used to characterize genetic diversity (Mahmoud et al., 2014), genetic structure (Rampersad, 2013; Gramaje et al., 2014), fingerprinting (identification) (Priyanka et al., 2014), population genetic structure (Hadrich et al., 2010), phylogenetic studies (Dutech et al., 2007), genome mapping (Chakravarty, 2011), and gene tagging (Ratnaparkhe et al., 1998).

In the present study, we aimed to 1) assess the characterization of the genetic diversity of $A$. flavus by using the ISSR-PCR technique, and 2) examine molecular relatedness among $A$. flavus isolates collected from seed borne fungi and air in Saudi Arabia and Egypt.

\section{MATERIAL AND METHODS}

\section{Fungal isolates}

Thirty isolates of $A$. flavus (Table 1) were collected from different sources. Twenty-five isolates were obtained from grains and seeds of agricultural crops, whereas five isolates were obtained from air. All isolates were from Saudi Arabia, except for five isolates from Egypt. A. flavus isolates were maintained and the production of mycelia was performed as described by Mahmoud et al (2014).

\section{Genomic DNA extraction of $A$. flavus isolates}

The A. flavus spore suspension $\left(10^{6}\right.$ spores $\left./ \mathrm{mL}\right)$ of every isolate was inoculated into double-layer (one solid and one liquid) media in 50-mm Petri dishes. The base solid medium was a film of PDA, and the top medium was liquid PYG. DNA was extracted according to the methods reported by Mahmoud (2015). 
Table 1. Isolates of Aspergillus flavus used in this study.

\begin{tabular}{|c|c|c|c|c|}
\hline No. & Accession & Origin & Source & Species name \\
\hline 1 & Co1 & Egypt & Cotton & A. flavus \\
\hline 2 & $\mathrm{Co} 2$ & Egypt & Cotton & A. flavus \\
\hline 3 & Co3 & Egypt & Cotton & A. flavus \\
\hline 4 & Co4 & Egypt & Cotton & A. flavus \\
\hline 5 & $\mathrm{Co5}$ & Egypt & Cotton & A. flavus \\
\hline 6 & S1 & Saudi Arabia & Sorghum & A. flavus \\
\hline 7 & S2 & Saudi Arabia & Sorghum & A. flavus \\
\hline 8 & S3 & Saudi Arabia & Sorghum & A. flavus \\
\hline 9 & S4 & Saudi Arabia & Sorghum & A. flavus \\
\hline 10 & S5 & Saudi Arabia & Sorghum & A. flavus \\
\hline 11 & S6 & Saudi Arabia & Sorghum & A. flavus \\
\hline 12 & A1 & Saudi Arabia & Air & A. flavus \\
\hline 13 & A2 & Saudi Arabia & Air & A. flavus \\
\hline 14 & A3 & Saudi Arabia & Air & A. flavus \\
\hline 15 & A4 & Saudi Arabia & Air & A. flavus \\
\hline 16 & A5 & Saudi Arabia & Air & A. flavus \\
\hline 17 & M1 & Saudi Arabia & Maize & A. flavus \\
\hline 18 & M2 & Saudi Arabia & Maize & A. flavus \\
\hline 19 & M3 & Saudi Arabia & Maize & A. flavus \\
\hline 20 & M4 & Saudi Arabia & Maize & A. flavus \\
\hline 21 & P1 & Saudi Arabia & Peanut & A. flavus \\
\hline 22 & $\mathrm{P} 2$ & Saudi Arabia & Peanut & A. flavus \\
\hline 23 & P3 & Saudi Arabia & Peanut & A. flavus \\
\hline 24 & $\mathrm{P} 4$ & Saudi Arabia & Peanut & A. flavus \\
\hline 25 & P5 & Saudi Arabia & Peanut & A. flavus \\
\hline 26 & Ca1 & Saudi Arabia & Cashew & A. flavus \\
\hline 27 & $\mathrm{Ca} 2$ & Saudi Arabia & Cashew & A. flavus \\
\hline 28 & Ca3 & Saudi Arabia & Cashew & A. flavus \\
\hline 29 & Ca4 & Saudi Arabia & Cashew & A. flavus \\
\hline 30 & Ca5 & Saudi Arabia & Cashew & A. flavus \\
\hline
\end{tabular}

PCR amplification and sequencing of the internal transcribed spacer regions (ITS1-5.8SITS2) was conducted.

Fungal isolates were molecularly identified by their ITS regions (ITS1-5.8S-ITS2), and 5.8S rRNA sequences. The primers ITS-1 (5'-TCCGTAGGTGAACCTGCGTG-3') and ITS-4 (5'-TCCTCCGCTTATTGATATGC-3') were used for PCR. PCR conditions follow the methods of Gehlot et al. (2011). PCR amplification was conducted using a T Personal Thermocycler (Biometra, Göttingen, Germany). The amplified PCR products were sequenced using an automated ABI-Prism 377 DNA Sequencer (Applied Biosystems Inc., CA, USA). The sequences were aligned with MEGA 7.01 software and compared with the nucleotide sequences in GenBank for final identification. The phylogenetic tree was constructed using the neighborjoining method (Saitou and Nei, 1987). Identification at the species level was based on ITS similarity as a percentage (Higgins et al., 2007).

\section{ISSR PCR}

PCR amplification of ISSRs was performed with the primers (GTG) $)_{5},(\mathrm{GACA})_{4}$, and $(A G A G)_{4} G$. The reaction amplifications were applied according to methods used by Mohamed et al. (2014). Sequences of primers are listed in Table 1. PCR products were loaded on a $1 \%$ agarose gel containing ethidium bromide in $1 \mathrm{X}$ TAE, then visualized with a gel documentation system (BioRad Laboratories, Inc., CA, USA). The DNA gel was scanned using AAB software (AAB Software Ltd., CA, USA) and a 100-bp DNA ladder (New England BioLabs Inc., Hitchin, UK) was used as a marker. The similarity level was determined using the UPGMA method. 


\section{RESULTS}

\section{Identification of isolates}

The two A. flavus isolates M3 and A5 (Figure 1) were identified and authenticated by molecular analysis of their ITS1, ITS2, and 5.8S rDNA regions. We inferred from the phylogenetic tree that $A$. flavus isolate M3 was classified into a clade that included A. flavus EU515148 and KF33940. The M3 isolate was closely related to $A$. flavus EU515148 with ITS sequence similarity of $99.9 \%$. $A$. flavus isolate A5 was classified into a clade that included $A$. flavus KF562199 and KJ433668. The A5 isolate was closely related to $A$. flavus KJ433668, with ITS sequence similarity of $99.9 \%$.
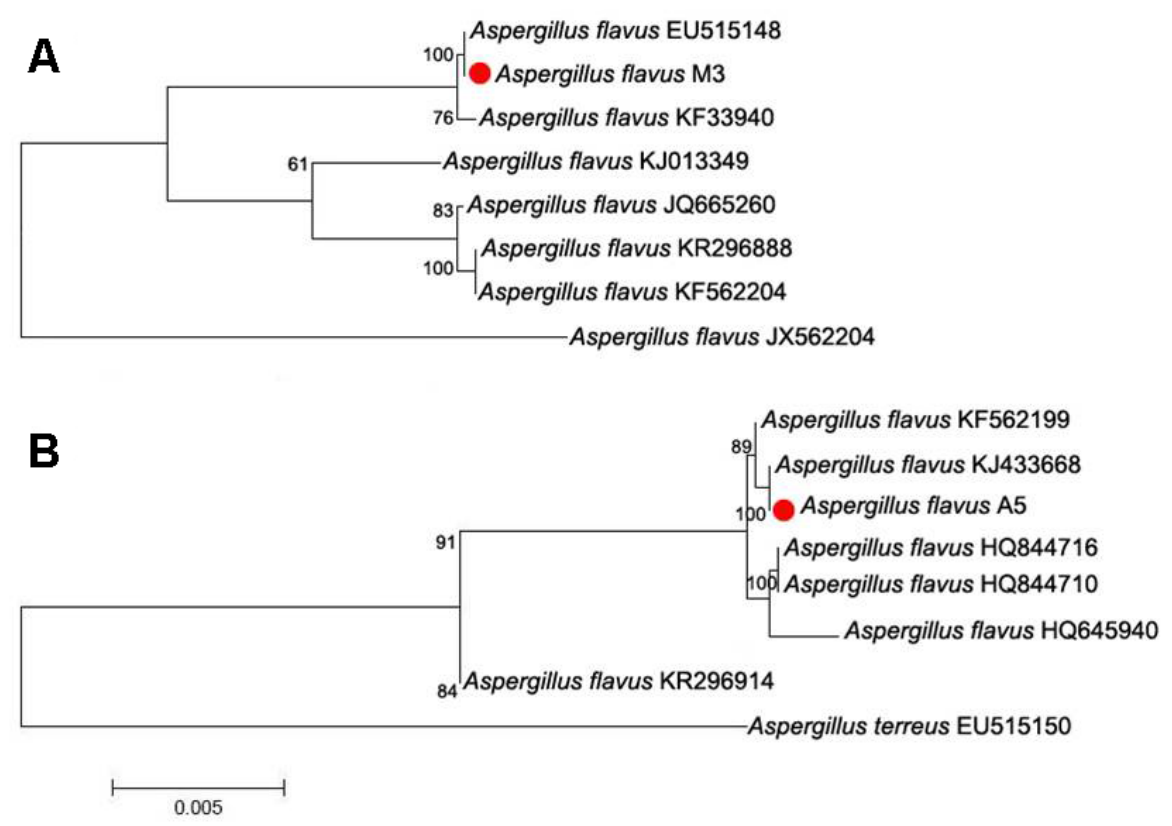

Figure 1. Phylogenetic tree of two Aspergillus flavus based on ITS region and 5.8S sequences. A. Isolate M3; B. isolate A5.

\section{Genetic diversity of $A$. flavus using the (GTG) ${ }_{5}$ primer}

A cluster analysis was executed based on the GSC, which ranged from 0.41 to 1.0 for the 30 isolates (Figure 2). A dendrogram grouped 30 isolates into four main clusters (labeled A-D) using the UPGMA method. Four clusters were had GSC values of 0.49. Cluster A consisted of eight isolates, all from Saudi Arabia. Isolates A1 and A3 were from the air, and P1 and P3 were from peanut. The isolate Ca4 was from cashew, S6 from sorghum, and M3 from maize. Cluster B included 14 isolates, 12 isolates from Saudi Arabia and two from Egypt. These 12 isolates were from a variety of sources such as cashew, sorghum, and peanut. Cluster $C$ included seven isolates, four isolates from Saudi Arabia and three from Egypt. Group C was divided into two subclusters. The first subcluster contained two isolates from cashew ( $\mathrm{Ca} 1$ and $\mathrm{Ca} 2$ ) and one isolate from cotton (Co3). The second subcluster contained two isolates from cotton (Co2 and Co5) and two from sorghum (S1 and S4). Cluster D had one isolate M2 (maize) from Saudi Arabia. 


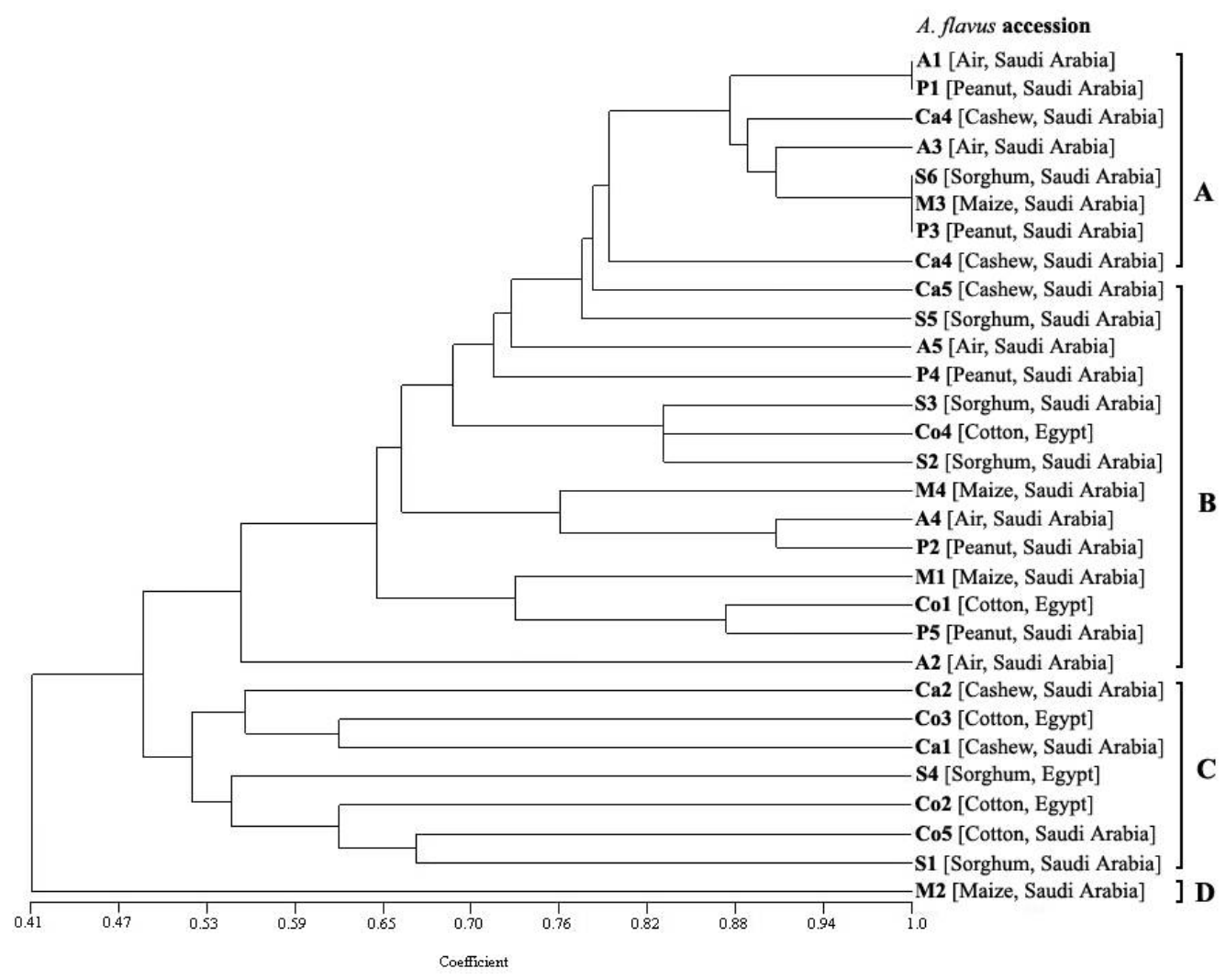

Figure 2. Dendrogram of 30 A. flavus isolates from UPGMA based on (GTG) ${ }_{5}$ primer

\section{Genetic diversity of $A$. flavus using the (GACA) ${ }_{4}$ primer}

The ISSR dendrogram was completed based on the GSC, which ranged from 0.29 to 1.0 for the 30 isolates (Figure 3). The ISSR dendrogram analysis grouped the 30 isolates into five main clusters (labeled A-F) using the UPGMA method. Five clusters were delineated at a GSC value of 0.38 . Cluster $A$ had the largest number of isolates (12 isolates), eleven from Saudi Arabia and one from Egypt. Cluster A was divided into two subclusters. The first subcluster contained nine isolates, and the second subcluster contained three isolates (M3, A4, and Co5). Cluster B included three isolates, all from Saudi Arabia. Cluster B consisted of A1, A2, and M1. Cluster C contained four isolates from Saudi Arabia: Ca4 and Ca5 (cashew), M2 (maize), and S5 (sorghum). Cluster $D$ included nine isolates from different sources such as cotton, sorghum, and air. Clusters $E$ and $F$ contained one isolate each: P2 (peanut) and S4 (sorghum), both from Saudi Arabia.

\section{Genetic diversity of $A$. flavus using the (AGAG) ${ }_{4}$, primer}

The dendrogram generated using the GSC had values that ranged from 0.00 to 1.0 for the 30 isolates (Figure 4). The ISSR banding pattern showed three clusters (A-C). These three clusters were delineated at a GSC value of 0.38 . 
The genetic relationships among the $30 \mathrm{~A}$. flavus isolates were also visualized by principal coordinate analysis of the three ISSR primers (Figure 5). The two-dimensional plot (Figure 5) generated from PCA supports the clustering pattern of the UPGMA dendrogram (Figure 5).

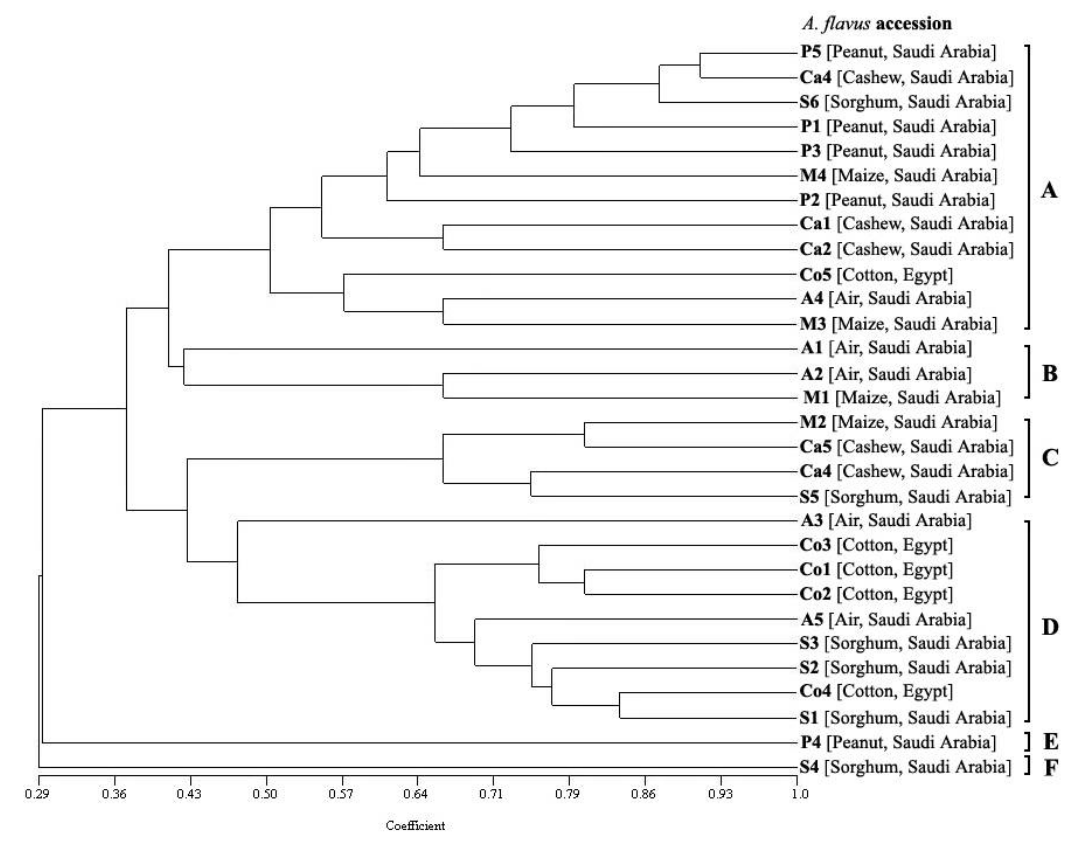

Figure 3. Dendrogram of $30 \mathrm{~A}$. flavus isolates from UPGMA based on (GACA) 4 primer.

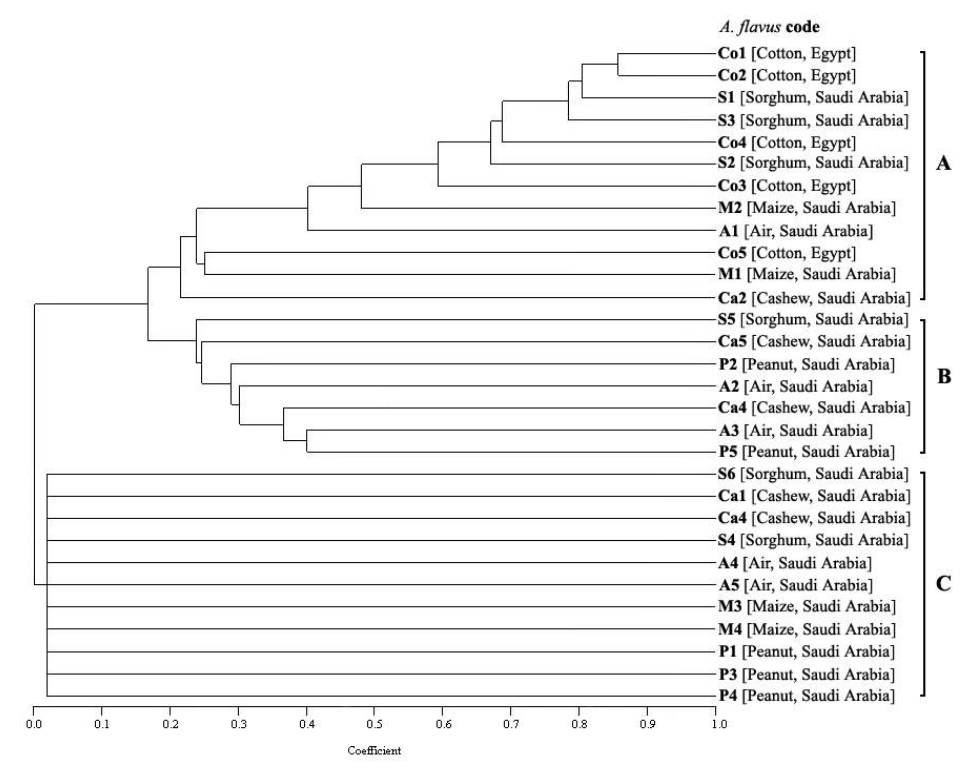

Figure 4. Dendrogram of $30 \mathrm{~A}$. flavus isolates from UPGMA based on (AGAG) ${ }_{4} \mathrm{G}$ primer. 


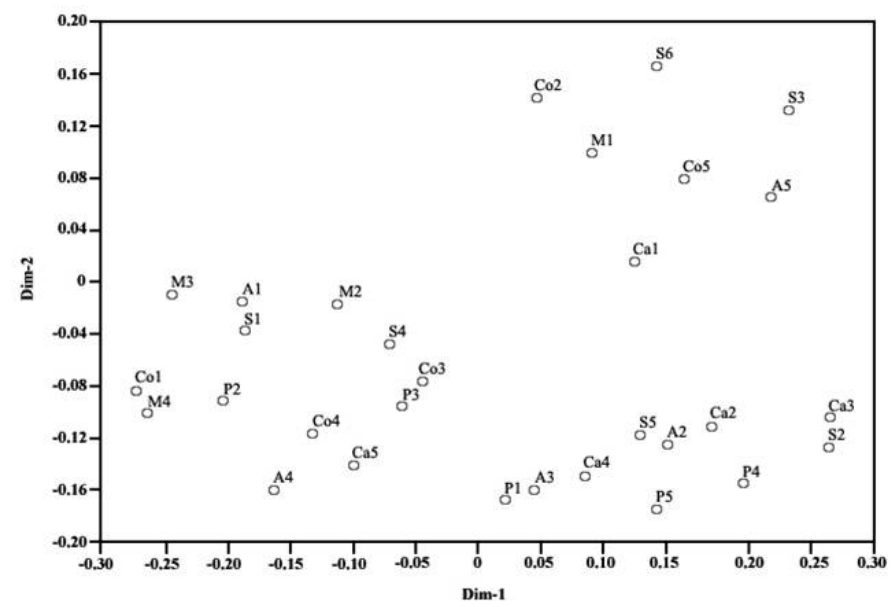

Figure 5. Principle coordinate analysis for 3 ISSR primers used to profile $30 \mathrm{~A}$. flavus isolates.

\section{DISCUSSION}

A. flavus infects humans, animals, and plants (Yu et al., 2005). Aspergillosis is an umbrella term used to describe a wide range of diseases of human and animals (Schabereiter-Gurtner et al., 2007). A. flavus has a broad host range and acts as an opportunistic pathogen/saprobe for any crop seed (wheat, corn, sorghum, cotton, rice, and peanut) (Klich, 2007; Mahmoud, 2014).

Airborne Aspergillus species are the predominant myco-pollutants of outdoor air in Saudi Arabia (El-Samawaty et al., 2012). ISSR is a suitable molecular marking technique for the study of genetic diversity of plants (Reddy et al., 2002), bacteria (Rayar et al., 2015), and fungi (Mahmoud et al., 2014). Thirty-four $A$. flavus isolates were recovered from sorghum seeds sampled in India. These isolates were assessed using molecular markers, such as b-tubulin, ITS, and ISSR, to characterize molecular diversity. ISSR analysis showed a high level of molecular diversity without relation to geographic region or chemotype of aflatoxin production (Divakara et al., 2015).

Fifty-two isolates of $A$. flavus were collected from three crops (peanut, maize, and pistachio) and different geographical regions of Iran. ISSR technology was used to determine genetic relatedness and polymorphism between isolates. A. flavus isolates exhibited high intraspecific variability and a significant number of polymorphisms. The varying similarity ranges within isolates of $A$. flavus could also be a result of isolates that share a host range and/or ecological niche (Houshyarfard et al., 2015).

Three ISSR primers were used to evaluate the genetic variability of $15 \mathrm{~A}$. flavus isolates from maize in Saudi Arabia. ISSR analysis revealed a high level of genetic diversity in the $A$. flavus population. The ISSR dendrograms obtained were unrelated to geographic origin or aflatoxin production (Mahmoud et al., 2014). Al-Wadai et al. (2013) obtained similar results from 13 A. flavus isolates from maize using the same three ISSR primers.

One hundred ISSR primers were evaluated for their ability to amplify DNA from $24 A$. flavus isolates.

Twenty-two primers succeeded in generating polymorphic bands for each primer. The study showed that ISSR technology is an effective molecular approach for studying the diversity of $A$. flavus from soil of peanut crops in China (Zhang et al., 2013). A microsatellite analysis of 
Vietnamese $A$. flavus strains (isolated from corn, peanut, and soil) revealed high genetic diversity. Clustering of microsatellite genotypes was unrelated to substrate and geographic origin or aflatoxin production (Tran-Dinh et al., 2009).

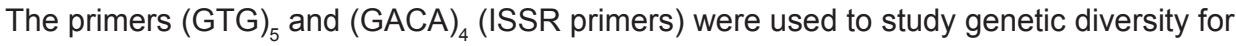
26 isolates of Aspergillus spp. ISSR markers detected high genetic diversity (inter- and intraspecific genetic variation), which is actually very useful as an auxiliary tool for genetic characterization of A. flavus strains (Batista et al., 2008).

\section{Conflicts of interest}

The authors declare no conflict of interest.

\section{ACKNOWLEDGMENTS}

The authors would like to extend their sincere appreciation to the Deanship of Scientific Research at King Saud University for its funding this research group (\#RG -1435-269).

\section{REFERENCES}

Abadio AKR, Lima SS, Santana MF, Salomão TMF, et al. (2012). Genetic diversity analysis of isolates of the fungal bean pathogen Pseudocercospora griseola from central and southern Brazil. Genet. Mol. Res. 11: 1272-1279.

Al-Wadai AS, Al-Othman MR, Mahmoud MA, Abd El-Aziz ARM (2013). Molecular characterization of Aspergillus flavus and aflatoxin contamination of wheat grains from Saudi Arabia. Genet. Mol. Res. 12: 3335-3352.

Batista PP, Santos JF, Oliveira NT, Pires AP, et al. (2008). Genetic characterization of Brazilian strains of Aspergillus flavus using DNA markers. Genet. Mol. Res. 7: 706-717. http://dx.doi.org/10.4238/vol7-3gmr422

Chakravarty B (2011). Trends in Mushroom cultivation and breeding. Am. J. Agric. Econ. 2: 102-109.

Chen YY, Zhou RC, Lin XD, Wu KQ, et al. (2008). ISSR analysis of genetic diversity in sacred lotus cultivars. Aquat. Bot. 89: 311-316.

Chhotaray A, Dhua U, Beheraa L and Mukherjeea AK (2015). Detection of seedborne Aspergillus flavus from rice cultivars using molecular markers. Arch. Phytopathol. PFL. 48: 297-305.

Divakara ST, Aiyaz M, Moore GG, Venkataramana M, et al. (2015). Analysis of genetic and aflatoxin diversity among Aspergillus flavus isolates collected from sorghum seeds. J. Basic Microbiol. 55: 1255-1264. http://dx.doi.org/10.1002/ jobm.201400951

Dutech C, Enjalbert J, Fournier E, Delmotte F, et al. (2007). Challenges of microsatellite isolation in fungi. Fungal Genet. Biol. 44: 933-949. http://dx.doi.org/10.1016/j.fgb.2007.05.003

El-Samawaty AMA, Bahkali HA, El-Naggar M and Yassin MA (2012). Aflatoxigenic Aspergillii in outdoor air of Riyadh city. Fresen. Environ. Bull. 21: 2587-2593.

Gehlot P, Purohit DK and Singh SK (2011). Molecular diagnostics of human pathogenic Aspergillus species. Indian J. Biotechnol. 10: 207-211.

Gramaje D, León M, Santana M, Crous PW, et al. (2014). Multilocus ISSR markers reveal two major genetic groups in Spanish and South African populations of the grapevine fungal pathogen Cadophora luteo-olivacea. PLoS One 9: e110417. http:// dx.doi.org/10.1371/journal.pone.0110417

Hadrich I, Makni F, Ayadi A and Ranque S (2010). Microsatellite typing to trace Aspergillus flavus infections in a hematology unit. J. Clin. Microbiol. 48: 2396-2401. http://dx.doi.org/10.1128/JCM.01269-09

Higgins KL, Arnold AE, Miadlikowska J, Sarvate SD, et al. (2007). Phylogenetic relationships, host affinity, and geographic structure of boreal and arctic endophytes from three major plant lineages. Mol. Phylogenet. Evol. 42: 543-555. http:// dx.doi.org/10.1016/j.ympev.2006.07.012

Houshyarfard M, Rouhani H, Falahati-Rastegar M, Malekzadeh-Shafaroudi S, et al. (2015). Characterization of Iranian nonaflatoxigenic strains of Aspergillus flavus based on microsatellite-primed PCR. Mol. Biol. Res. Commun. 4: 43-55.

Klich MA (2007). Aspergillus flavus: the major producer of aflatoxin. Mol. Plant Pathol. 8: 713-722. http://dx.doi.org/10.1111/ j.1364-3703.2007.00436.x

Kumar LS (1999). DNA markers in plant improvement: an overview. Biotechnol. Adv. 17: 143-182. http://dx.doi.org/10.1016/ S0734-9750(98)00018-4 
Mahmoud MA (2015). Detection of Aspergillus flavus in stored peanuts using real-time PCR and the expression of aflatoxin genes in toxigenic and atoxigenic A. flavus isolates. Foodborne Pathog. Dis. 12: 289-296. http://dx.doi.org/10.1089/ fpd.2014.1854

Mahmoud MA, Ali HM, El-Aziz ARM, Al-Othman MR, et al. (2014). Molecular characterization of aflatoxigenic and nonaflatoxigenic Aspergillus flavus isolates collected from corn grains. Genet. Mol. Res. 13: 9352-9370. http://dx.doi. org/10.4238/2014.November.11.2

Mohankumar M, Vijayasamundeeswari A, Karthikeyan M, Mathiyazhagan S, et al. (2010). Analysis of molecular variability among isolates of Aspergillus flavus by PCR-RFLP of the ITS regions of rDNA. J. Plant Prot. Res. 50: 446-451. http:// dx.doi.org/10.2478/v10045-010-0075-4

Mushtaq S, Akram A, Hanif NQ, Qureshi RT, et al. (2015). Natural incidence of aflatoxins, mycological profile and molecular characterization of aflatoxigenic strains in chickpea flour. Pak. J. Bot. 47: 1153-1160.

Prince LM (2015). Plant genotyping using fluorescently tagged inter-simple sequence repeats (ISSRs): basic principles and methodology. Methods Mol. Biol. 1245: 63-75. http://dx.doi.org/10.1007/978-1-4939-1966-6 5

Priyanka SR, Uppalapati SR, Kingston JJ, Murali HS, et al. (2014). Development of ISSR-derived SCAR marker-targeted PCR for identification of Aspergillus section Flavi members. Lett. Appl. Microbiol. 58: 414-422. http://dx.doi.org/10.1111/ $\underline{\text { lam. } 12207}$

Rampersad SN (2013). Genetic structure of Colletotrichum gloeosporioides sensu lato isolates infecting papaya inferred by multilocus ISSR markers. Phytopathology 103: 182-189. http://dx.doi.org/10.1094/PHYTO-07-12-0160-R

Ratnaparkhe MB, Tekeoglu M and Muehlbauer FJ (1998). Inter-simple-sequence-repeat (ISSR) polymorphisms are useful for finding markers associated with disease resistance gene clusters. Theor. Appl. Genet. 97: 515-519. http://dx.doi. org/10.1007/s001220050925

Rayar JK, Arif M and Singh US (2015). Relative efficiency of RAPD and ISSR markers in assessment of DNA polymorphism and genetic diversity among Pseudomonas strains. Afr. J. Biotechnol. 14: 1097-1106. http://dx.doi.org/10.5897/AJB10.1951

Reddy MP, Sarla N and Siddiq EA (2002). Inter simple sequence repeat (ISSR) polymorphism and its application in plant breeding. Euphytica 128: 9-17. http://dx.doi.org/10.1023/A:1020691618797

Saitou N and Nei M (1987). The neighbor-joining method: a new method for reconstructing phylogenetic trees. Mol. Biol. Evol. 4: 406-425.

Schabereiter-Gurtner C, Selitsch B, Rotter ML, Hirschl AM, et al. (2007). Development of novel real-time PCR assays for detection and differentiation of eleven medically important Aspergillus and Candida species in clinical specimens. J. Clin. Microbiol. 45: 906-914. http://dx.doi.org/10.1128/JCM.01344-06

Singh D, Radhakrishnan T, Kumar V, Bagwan NB, et al. (2015). Molecular characterisation of Aspergillus flavus isolates from peanut fields in India using AFLP. Braz. J. Microbiol. 46: 673-682. http://dx.doi.org/10.1590/S1517-838246320131115

Tran-Dinh N, Kennedy I, Bui T and Carter D (2009). Survey of Vietnamese peanuts, corn and soil for the presence of Aspergillus flavus and Aspergillus parasiticus. Mycopathologia 168: 257-268. http://dx.doi.org/10.1007/s11046-009-9221-9

Varga J (2006). Molecular typing of aspergilli: Recent developments and outcomes. Med. Mycol. 44: S149-S161. http://dx.doi. org/10.1080/13693780600823266

Wang X, Wadl PA, Wood-Jones A, Windham G, et al. (2012). Characterization of expressed sequence tag-derived simple sequence repeat markers for Aspergillus flavus: emphasis on variability of isolates from the southern United States. Mycopathologia 174: 371-382. http://dx.doi.org/10.1007/s11046-012-9573-4

Yu J, Cleveland TE, Nierman WC and Bennett JW (2005). Aspergillus flavus genomics: gateway to human and animal health, food safety, and crop resistance to diseases. Rev. Iberoam. Micol. 22: 194-202. http://dx.doi.org/10.1016/S11301406(05)70043-7

Zhang C, Xing F, Selvaraj JN, Yang Q, et al. (2013). The effectiveness of ISSR profiling for studying genetic diversity of Aspergillus flavus from peanut-cropped soils in China. Biochem. Syst. Ecol. 50: 147-153. http://dx.doi.org/10.1016/j. $\underline{\text { bse.2013.03.046 }}$ 